\title{
Generation of Human Antibodies Against a Specific Peptide: a Novel Strategy Based on Human Cells
}

\author{
MARIA TOLOUDI, MARIA PAPADIMITRIOU, KATERINA PANTOPIKOU and IOANNIS PAPASOTIRIOU \\ Research Genetic Cancer Centre Group, Florina, Greece
}

\begin{abstract}
Background/Aim: We developed a novel platform to produce fully human antibodies that could be used as tools in cancer research. This study was based on maturation of B-cells into plasma cells and the subsequent secretion of fully human antibodies against a 9-mer peptide. Materials and Methods: A peptide was introduced to dendritic cells, followed by co-cultivation with cluster of differentiation 4 $(\mathrm{CD} 4+)$ cells from healthy donors and $\mathrm{CD} 19^{+}$cells from patients with cancer. In order to detect plasma cells, we used microscopy, flow cytometry, enzyme-linked immunosorbent assays (ELISAs), and western blotting. Results. Oval-shaped cells with eccentric nuclei were found which expressed high levels of CD27 (up to 73\%) and CD138 (up to 31\%). An antibody against the selected peptide was detected in the culture supernatants of all samples according to ELISA and western blot analyses. Conclusion: This platform successfully generated fully human antibodies against a specific epitope.
\end{abstract}

Monoclonal antibody technology has become an important part of biopharmaceuticals. The first mouse monoclonal antibody was Orthoclone OKT3 [muromonab- cluster of differentiation 3 (CD3)]. It was approved in 1986 for use in preventing kidney transplant rejection. Its isotype was $\operatorname{IgG}_{2 a}$ and worked by blocking CD3 on T-lymphocytes. Subsequently, many monoclonal antibodies have been produced, approved, and used in clinical practice (1). However, many side-effects have been reported, such as low blood pressure, fever, chills, and weakness. Therefore, the technology evolved from murine to humanized and human antibodies that resemble naturally occurring antibodies (2). Except for humanization of a host cell, such as of mouse,

Correspondence to: Ioannis Papasotiriou, MD, Ph.D., Head of Molecular Medicine of Research Genetic Cancer Centre. Florina, Greece. Tel.:+30 2385041950, Fax: +30 2385041931, e-mail: papasotiriou.ioannis@rgcc-genlab.com,office@rgcc-genlab.com

Key Words: Monoclonal antibodies, breast cancer. rabbit, chicken, goat and rat, which is the most widely used method; some studies have reported new platforms for the generation of plasma cells to produce antibodies. Human Bcells in parallel with Epstein-Barr virus are used to generate large numbers of IgGs (3). The progress of monoclonal antibody production has been reviewed recently $(4,5)$. Nevertheless, the present platform differs from previous strategies because it involves the sole use of human cells, rendering the monoclonal antibodies fully human.

The present study generated a fully human monoclonal antibody against a selected peptide by a population of plasma cells. The procedure was based on the fact that B-cells $\left(\mathrm{CD} 19^{+}\right)$normally mature into plasma cells via interaction with $\mathrm{CD} 4^{+} \mathrm{T}$-helper cells when both are activated by the same epitope (6). Plasma cells are responsible for the production of all antibodies in circulation. Normally, very low numbers of plasma cells $(2 / \mu \mathrm{l})$ are found in the peripheral blood of healthy donors (7). In order to maximize their number and secreted products in vitro, an interaction must occur between a population of antigen-presenting cells, $\mathrm{CD}^{+}{ }^{+}$T-helper cells, and $\mathrm{CD} 19^{+}$cells. Activated B-cells become either memory B-cells or plasma cells. Therefore, a group of factors is required to drive differentiation of $\mathrm{CD} 19^{+}$ cells into plasma cells.

Two of the main stimuli of B-cells in vitro are anti-IgM and anti-CD40 ligands. It has been shown that they induce plasma cell differentiation upon interaction with interleukin (IL)-21 . Other cytokines, which may be correlated with the generation of plasma cells, are IL2, IL6, and IL10. Moreover, the interplay between IL21 and IL4 may be essential in determining the outcome of immune responses (8).

In order to define antibody-secreting plasma cells, the expression of a group of surface antigens needs to be tested. The B-cell maturation process correlates with the expression of CD19, CD20, CD27, CD38 and CD138 (9). In most cases, the generated oval-shaped cells are $\mathrm{CD} 27^{+} \mathrm{CD} 38^{+} \mathrm{CD} 138^{+}$.

Two methods are employed for detecting such compounds in culture supernatants. The first one is the enzyme-linked immunosorbent assay (ELISA), a useful and powerful method for estimating concentrations ranging from $\mathrm{pg} / \mathrm{ml}$ to 
$\mathrm{ng} / \mathrm{ml}$ in solutions such as serum, urine and culture supernatants, depending on the assay. The basic principle is the use of an enzyme to detect the binding of an antigen or antibody. The enzyme converts a colourless substrate (chromogen) to a coloured product, indicating the presence of an antigen-antibody interaction. An ELISA can be used to detect either antigens or antibodies in a sample, depending on the design. The second well-characterized method is western blotting, also called immunoblotting because an antibody is used to specifically detect its antigen. The specificity of the antibody-antigen interaction enables a target protein to be identified in a complex protein mixture. Western blotting can produce qualitative and semiquantitative data about the target protein.

In summary, our platform uses only human cells to generate plasma cells for the production of fully human antibodies against a specific epitope.

\section{Materials and Methods}

Blood sample collection. Freshly isolated ( $<24 \mathrm{~h}$ after collection) blood samples from seven healthy donors were used to generate dendritic cells (DCs) from monocytes and to enrich $\mathrm{CD}^{+}+$cells from the same donor. Blood was collected in vacutainers containing anticoagulants (heparin, EDTA, citrate, acid citrate dextrose) or citrate phosphate dextrose. To isolate the $\mathrm{CD} 19^{+}$cell population, blood samples were obtained from patients with breast (five patients) or prostate (two patients) cancer. The transit of the samples to the laboratory did not exceed 6 days. Informed consent was provided by all donors.

Human peripheral blood mononuclear cell (PBMC) isolation and counting. In order to isolate PBMCs, we used Biocoll separation solution (Biochrom, Cambridge, UK). Anticoagulant-treated peripheral blood or buffy coat $(10-15 \mathrm{ml})$ were diluted in an equal volume of phosphate-buffered saline (PBS; Sigma, Munich, Germany) and carefully layered over $15 \mathrm{ml}$ of Biocoll. After centrifugation $(420 \times g$ for $30 \mathrm{~min})$, the intermediate layer containing the monocytes was collected and washed with three volumes of PBS. The cells were then centrifuged at $170 \times g$ for $10 \mathrm{~min}$, and the cell pellet was resuspended in $1 \mathrm{ml}$ of RPMI medium (Sigma) supplemented with 10\% foetal bovine serum (FBS, FB-1001/500; BioSera, Boussens, France). The isolated cells were counted using an NC-100+ NucleoCounter system (Chemometec, Allerød, Denmark) or Neubauer chamber.

DC generation. To generate DCs, the isolated PBMCs were plated in a $25-\mathrm{cm}^{2}$ flask in serum-free X-VIVO 20 medium (Lonza, Blackley, UK) containing $500 \mathrm{U} / \mathrm{ml}$ IL4 (R\&D Systems, Abingdon, $\mathrm{UK}), 800 \mathrm{U} / \mathrm{ml}$ granulocyte-macrophage colony-stimulating factor (GM-CSF; Gentaur, Kampenhout, Belgium), and 1,000 U/ml tumour necrosis factor- $\alpha$ (TNF $\alpha$; PeproTech, Rocky Hill, UK). They were then incubated for 7 days at $37^{\circ} \mathrm{C}$ with $5 \% \mathrm{CO}_{2}$. After incubation, the cells were harvested and tested for CD80/CD86 expression by flow cytometry to confirm the presence of DCs.

$\mathrm{CD}^{+}$cell enrichment. The RosetteSep ${ }^{\circledR}$ Human CD4 ${ }^{+} \mathrm{T}-\mathrm{Cell}$ Enrichment Cocktail (StemCell Technologies, Grenoble, France) was used to enrich $\mathrm{CD}^{+}$cells from blood of the same healthy donors used for DC generation, according to the protocol provided by the manufacturer. Blood samples $(10 \mathrm{ml})$ were applied to the protocol. Cells were counted using the NC-100+ NucleoCounter system or a Neubauer chamber.

$\mathrm{CD} 9^{+}$cell isolation from patients with cancer. A two-step isolation procedure was used to isolate $\mathrm{CD} 19^{+}$cells from 10-ml samples of blood obtained from cancer patients. PBMCs were first isolated using Biocoll separation solution. The PBMCs were sorted to collect the lymphocyte population. The cells were selected without antibodies using a template with a bivariate plot to display forward and side scatter. A gate around the desired cell population was drawn on the dot plot, and the cells were sorted into external collection tubes. The collected cells were centrifuged at $170 \times g$ for 5 min. CD19+ cell isolation was performed using anti-human CD19 magnetic beads (BD Bioscience, Milano, Italy). Magnetic beads (50 $\mu \mathrm{l})$ were added to $1 \times 10^{7}$ cells, followed by incubation at room temperature for $30 \mathrm{~min}$. The tube was then placed on a magnet for $10 \mathrm{~min}$, and then the supernatant was aspirated off. After a second step on the magnet, the selected cells were the cells of interest. A $\mathrm{CD} 19^{+}$flow cytometric test was performed before and after the two separation steps.

Transfection. Transfection of DCs with a 9-mer peptide $(\mathrm{H}-$ AAAAAAAAA-OH, A indicates amino acid) was achieved using PromoFectin-Polypeptide Cell Transfection Reagent (Promokine, Nürnberg, Germany). The peptide consisted of four amino acids with a hydrophobic chain, three with a polar uncharged side chain, one with a positive charge, and a glycine. The preparation of PromoFectin-Polypeptide/peptide complexes was conducted according to the manufacturer's instructions. The peptide was diluted in PBS at the recommended concentration $(5.1 \mathrm{mg} / \mathrm{ml})$. The final concentration for the transfection procedure was $78 \mu \mathrm{g} / \mathrm{ml}$. A 10:1 PromoFectin:peptide ratio was used according to the manufacturer's instructions. The selection of the peptide was based on the fact that this specific epitope might play an important role in cancer progression. Therefore, generating an antibody against the peptide may facilitate limiting cancer effects.

After generating DCs and testing by flow cytometry as described above, the cells were plated in a $25-\mathrm{cm}^{2}$ flask with serum-free RPMI medium and incubated for $1-2 \mathrm{~h}$ at $37^{\circ} \mathrm{C}$ to allow attachment to the flask surface. The complex was then introduced into DCs by incubation for at least $4 \mathrm{~h}$. Cells were cultured for up to 12 days to perform all analyses.

Co-cultivation of $\mathrm{DCs}, \mathrm{CD}^{+}{ }^{+}$and $\mathrm{CD} 9^{+}$cells. The co-cultivation procedure for the three cell populations started after peptide transfection. $\mathrm{CD}^{+}{ }^{+}$and $\mathrm{CD} 19^{+}$cells were co-cultivated with DCs in medium supplemented with $100 \mathrm{U} / \mathrm{ml}$ IL2 (Abcam, Cambridge, UK), $100 \mathrm{ng} / \mathrm{ml} \mathrm{IL4} \mathrm{(R \& D} \mathrm{Systems),} 100 \mathrm{ng} / \mathrm{ml} \mathrm{IL21} \mathrm{(Sigma),} 25$ $\mathrm{ng} / \mathrm{ml}$ IL20 (Sigma), $1 \mu \mathrm{g} / \mathrm{ml}$ anti-CD40L (Acris Antibodies, Herford, Germany), and $5 \mu \mathrm{g} / \mathrm{ml}$ anti-IgM antibody (Antibodies On Line, Aachen, Germany). The co-cultures were incubated at $37^{\circ} \mathrm{C}$ with $5 \% \mathrm{CO}_{2}$ for 12 days.

Cell evaluation by flow cytometry. Flow cytometry was used to test the expression of surface antigens. The $\mathrm{CD} 80^{+} / \mathrm{CD} 86^{+}$doublepositive population among mature DCs was first tested using human anti-CD80 R-phycoerythrin (PE) and human anti-CD86-fluorescein 
Table I. Healthy donor characteristics and cell numbers.

\begin{tabular}{lccccc}
\hline Healthy donor ID & Age, years & Gender & Blood collection (ml) & Total number of PBMCs & PBMC density (cells/ml) \\
\hline 1 & 22 & F & 10 & $3,645,000$ & $0.81 \times 10^{6}$ \\
8 & 26 & F & 15 & $9,700,000$ & $0.97 \times 10^{6}$ \\
13 & 22 & F & 14 & $8,175,000$ & $1.63 \times 10^{6}$ \\
14 & 22 & F & 14 & $8,175,000$ & $1.63 \times 10^{6}$ \\
15 & 25 & F & 10 & $5,700,000$ & $1.14 \times 10^{6}$ \\
16 & 29 & M & 9 & $22,125,000$ & $2.21 \times 10^{6}$ \\
17 & 29 & M & 9 & $22,125,000$ & $2.21 \times 10^{6}$ \\
\hline
\end{tabular}

F: Female; M: male; PBMC: peripheral blood mononuclear cells.

(FITC) (Life Technologies, Waltham, MA USA) antibodies. The $\mathrm{CD} 19+$ cell population was detected using an anti-hCD19-FITC antibody (R\&D Systems). In order to evaluate the presence of plasma cells, we tested five surface antigens using antibodies against CD19 (R \&D Systems), CD20 (Abd Serotec, Kidlington, $\mathrm{UK}), \mathrm{CD} 27$ (EBioscience, Athens, Greece), CD38 (EBioscience) and CD138 (EBioscience). This test is referred to as the 'panel of 5 ' test in this study.

Microscopy. After co-cultivation, the cells were observed under an inverted microscope (Primovert, Carl Zeis) to confirm the presence of plasma cells.

Detection of the selected peptide by ELISA. To detect the 9-mer peptide in culture supernatants, we established an ELISA specific for the peptide. Firstly, a protein including the sequence of the selected peptide was coated on 96-well plates for $24 \mathrm{~h}$ at $4^{\circ} \mathrm{C}$. After two washes with ELISA Wash Buffer (Thermo Scientific, Waltham, MA USA) diluted at 1:30 in water, a blocking step was performed using ELISA Blocker Blocking Buffer (Thermo Scientific) for $1 \mathrm{~h}$ at room temperature. The primary antibody was added, followed by incubation for $1 \mathrm{~h}$ at room temperature. After two washes, the appropriate secondary antibody conjugated with horseradish peroxidase was added, followed by incubation in the dark for $1 \mathrm{~h}$. After two washes, 3,3',5,5'-tetramethylbenzidine (TMB) substrate solution (Thermo Scientific, Sindos, Greece) was added, followed by incubation for $15 \mathrm{~min}$ in the dark. To stop the reaction, Stop solution for TMB substrate (Thermo Scientific) was added. The absorbance was determined at $450 \mathrm{~nm}$ using a $\mu$ Quant microplate spectrophotometer (Biotek, Thessaloniki, Greece). All reactions were performed in duplicate and repeated twice.

Western blot analysis. In order to test for the presence of antibodies against the selected peptide in culture supernatants, $5 \mu \mathrm{g}$ of the protein including the sequence of the peptide was combined with an equal volume of loading buffer and loaded onto a discontinuous polyacrylamide gel. For the positive control, a goat anti-human antibody was used as the primary antibody and a rabbit anti-goat antibody was used as the secondary antibody. For the negative control, no primary antibody was added. To determine the molecular weight of the proteins, we used a Precision Plus Protein ${ }^{\text {TM }}$ All Blue Prestained Protein Standards ladder (BioRad, Athens, Greece). The gel was run at $180 \mathrm{~V}$ for $50 \mathrm{~min}$. After electrophoresis, the proteins were transferred to a nitrocellulose membrane using a semi-dry apparatus for $1 \mathrm{~h}$ at $10 \mathrm{~V}$. To confirm protein transfer, the membrane was stained with ponceau (Sigma) for $5 \mathrm{~min}$ and then washed with water until the protein bands were well defined. The membrane was washed three times ( $5 \mathrm{~min}$ each) with Tris buffered-saline - Tween 20 (TBS-T) and then blocked with 3\% blocking grade blocker/TBS$\mathrm{T}$ for $30 \mathrm{~min}$. Then the membrane was washed three times $(5 \mathrm{~min}$ each wash) in TBS-T and incubated overnight with the sample [50 $\mu \mathrm{l}$ of culture supernatant diluted in $5 \mathrm{ml}$ (1:100 dilution) of $1 \%$ bovine serum albumin (BSA)-TBS-T]. The day after incubation the membrane was washed three times in TBS-T, and incubated for $2 \mathrm{~h}$ with an appropriate secondary antibody (anti-human alkaline phosphate) diluted in 1\% BSA-TBS-T $(1: 10,000)$. The membrane was washed again and incubated with 5-bromo-4-chloro-3-indolylphosphate/4-nitro-blue tetrazolium chloride solution (Sigma), for 14 min until the desired colour was obtained. The reaction was stopped by extensive washing with water. Bands were detected and analyzed using Image Lab software version 3 (BioRad).

\section{Results}

Donor characteristics. In order to generate the DC population, peripheral blood was collected from seven healthy individuals, five females and two males. Their age ranged from 22 to 29 years. For monocyte isolation, the blood was freshly isolated. To prevent coagulation, the samples were collected in tubes (BD Falcon, 12×75 mm, 5ml Polystyrene Round Bottom Tube, 352054, Becton Dickinson Greece) containing EDTA and rotated for approximately $20 \mathrm{~min}$ before testing. The PBMC density ranged from $0.81 \times 10^{6}$ to $2.21 \times 10^{6}$ cells $/ \mathrm{ml}$, depending on the blood volume and donor (Table I).

For isolation of CD19 cells, peripheral blood was collected from seven patients at various stages of cancerfive females with breast cancer and two males with prostate cancer. Their ages ranged from 27 to 101 years. For CD19 ${ }^{+}$ cell isolation, blood was collected 6 days prior in tubes containing EDTA and rotated for approximately $20 \mathrm{~min}$ before testing (Table II).

Transfection and co-cultivation conditions. DCs were harvested after 7 days of incubation in X-VIVO medium 
Table II. Patient characteristics and cancer type.

\begin{tabular}{lccccc}
\hline $\begin{array}{l}\text { Cancer patient } \\
\text { ID }\end{array}$ & $\begin{array}{c}\text { Age, } \\
\text { years }\end{array}$ & $\begin{array}{c}\text { Gender } \\
\begin{array}{c}\text { Blood collection } \\
(\mathrm{ml})\end{array}\end{array}$ & $\begin{array}{c}\text { Cancer } \\
\text { type }\end{array}$ & Stage \\
\hline $\mathrm{A}$ & 64 & $\mathrm{~F}$ & 10 & Breast & I/II \\
$\mathrm{G}$ & 73 & $\mathrm{~F}$ & 15 & Breast & III \\
$\mathrm{J}$ & 81 & $\mathrm{~F}$ & 5 & Breast & $\mathrm{IV}$ \\
$\mathrm{K}$ & 81 & $\mathrm{~F}$ & 5 & Breast & $\mathrm{IV}$ \\
$\mathrm{L}$ & 27 & $\mathrm{~F}$ & 10 & Breast & $\mathrm{IV}$ \\
$\mathrm{M}$ & 101 & $\mathrm{M}$ & 5 & Prostate & $\mathrm{I} / \mathrm{II}$ \\
$\mathrm{N}$ & 101 & $\mathrm{M}$ & 5 & Prostate & $\mathrm{I} / \mathrm{II}$ \\
\hline
\end{tabular}

F: Female; M: male.

Table III. Transfected and co-cultivated sample IDs.

\begin{tabular}{llcc}
\hline $\begin{array}{l}\text { Healthy donor } \\
\text { ID }\end{array}$ & $\begin{array}{c}\text { Cancer patient } \\
\text { ID }\end{array}$ & $\begin{array}{c}\text { Sample } \\
\text { ID }\end{array}$ \\
\hline 1 & Co-cultivated with & $\mathrm{A}$ & $1 \mathrm{~A}$ \\
8 & Co-cultivated with & $\mathrm{G}$ & $8 \mathrm{G}$ \\
13 & Co-cultivated with & $\mathrm{J}$ & $13 \mathrm{~J}$ \\
14 & Co-cultivated with & $\mathrm{K}$ & $14 \mathrm{~K}$ \\
15 & Co-cultivated with & $\mathrm{L}$ & $15 \mathrm{~L}$ \\
16 & Co-cultivated with & $\mathrm{M}$ & $16 \mathrm{M}$ \\
17 & Co-cultivated with & $\mathrm{N}$ & $17 \mathrm{~N}$ \\
\hline
\end{tabular}

supplemented with GM-CSF, IL4, and TNF $\alpha$. Before transfection with the 9-mer peptide, DCs were analyzed by flow cytometry for protein expression of CD80 and CD86 surface markers (data not shown). The DCs were seeded in either a 12 -well plate or $25-\mathrm{cm}^{2}$ flask, depending on the number, for about $2 \mathrm{~h}$ at $37^{\circ} \mathrm{C}$ with $5 \% \mathrm{CO}_{2}$. The transfection protocol was performed at the end of the incubation.

After transfection, the DCs were co-cultivated with $\mathrm{CD}^{+}{ }^{+}$ cells isolated from the same healthy donor and $\mathrm{CD} 19^{+}$cells isolated from each patients with cancer. The transfected and co-cultivated sample IDs are indicated in Table III For all patients, the $\mathrm{DC}: \mathrm{CD}^{+}$cell ratio ranged from 1:0.08 to 1:0.48 except for patient $1 \mathrm{~A}(1: 13)$ (Table IV).

Microscopic analysis of plasma cell production. Mature plasma cells are often oval or fan shaped, with the ability to secrete large amounts of antibodies against specific antigens. Their nucleus is small, dense, eccentric and oval in shape. Plasma cell populations were detected in all co-cultivated samples (Figure 1) after 12 days of incubation.

Flow cytometric analysis. Mature Bcells are identified by the expression of several surface antigens during their maturation. Plasma cells commonly express CD27, CD38,
Table IV. Cell numbers in the co-cultivation procedure.

\begin{tabular}{|c|c|c|c|c|}
\hline \multirow{3}{*}{ Sample ID } & \multicolumn{3}{|c|}{ Number of cells for co-cultivation } & \multirow{3}{*}{$\begin{array}{c}\text { Cancer patients } \\
\text { CD19+ } \\
\text { cells }\end{array}$} \\
\hline & \multicolumn{3}{|c|}{ Healthy donors } & \\
\hline & DCs & $\mathrm{CD} 4^{+}$cells & $\begin{array}{l}\text { DC:CD4 }{ }^{+} \\
\text {cell ratio }\end{array}$ & \\
\hline $1 \mathrm{~A}$ & 42,000 & 540,000 & $1: 13$ & $3,565,364$ \\
\hline $8 \mathrm{G}$ & $2,910,000$ & $1,470,000$ & $1: 0.5$ & 190,000 \\
\hline $13 \mathrm{~J}$ & $16,992,000$ & $8,175,000$ & $1: 0.48$ & $24,160,000$ \\
\hline $14 \mathrm{~K}$ & $17,856,000$ & $8,175,000$ & $1: 0.45$ & $24,160,000$ \\
\hline $15 \mathrm{~L}$ & $13,360,000$ & $5,496,000$ & $1: 0.41$ & 263,775 \\
\hline $16 \mathrm{M}$ & $24,192,000$ & $1,824,000$ & $1: 0.08$ & $19,680,000$ \\
\hline $17 \mathrm{~N}$ & $7,392,000$ & $1,824,000$ & $1: 0.24$ & $19,680,000$ \\
\hline
\end{tabular}

DCs: Dendritic cells CD: cluster of differentiation.

CD138 and low levels of CD19 but do not express CD20. At day 12 of co-cultivation, the cells were stained for the markers mentioned above by flow cytometry (Figure 2). Reprehensive expression of CD138 is shown in Figure 3.

The percentage of cells positive for CD20 was very low in all samples except for 8G. Very low expression of CD19 (ranging from $0.02 \%$ to $0.96 \%$ ) was observed in all samples, with only two samples (1A and $8 \mathrm{G}$ ) expressing CD19 in $5.35 \%$ and $12.21 \%$ of cells, respectively. Based on the percentage range of the three major plasma cell markers (CD27, CD38, and CD138), samples were categorized into three groups. In the first group, the percentage of cells expressing all markers ranged from $0.1 \%$ to $0.95 \%$, in the second group from $1 \%$ to $9 \%$, and in the third group from $10 \%$ to $73 \%$. For CD27, only two samples (14K and $15 \mathrm{~L}$ ) were in the first group, four samples $(1 \mathrm{~A}, 13 \mathrm{~J}, 16 \mathrm{M}$, and $17 \mathrm{~N})$ in the second group, and one sample $(8 \mathrm{G})$ in the third group. For CD38, three samples $(15 \mathrm{~L}, 16 \mathrm{M}$, and $17 \mathrm{~N})$ were in the first group, one sample (14K) in the second group, and three samples (1A, 8G, and 13J) in the third group. Finally, for CD138, only one sample (15L) was in the first group, two samples $(16 \mathrm{M}$ and $17 \mathrm{~N})$ in the second group, and four samples $(1 \mathrm{~A}, 8 \mathrm{G}, 13 \mathrm{~J}$, and $14 \mathrm{~K})$ in the third group (Figure 4).

ELISA results. A typical standard curve was constructed for each experiment. The $\mathrm{x}$-axis represented the concentration of the primary antibody used to prepare the standard curve and the $y$-axis represented the optical density (OD) at $450 \mathrm{~nm}$. Based on the $\mathrm{OD}_{450}$ values, the levels of produced antibody in the tested samples was almost the same (OD450: 2.8) (data not shown).

Although this method has many advantages, such as sensitivity, flexibility of antibodies, and being less time- 


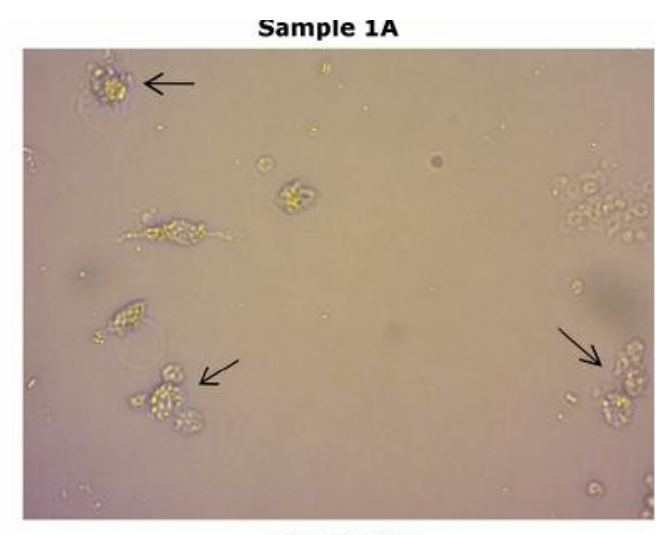

Sample 13J

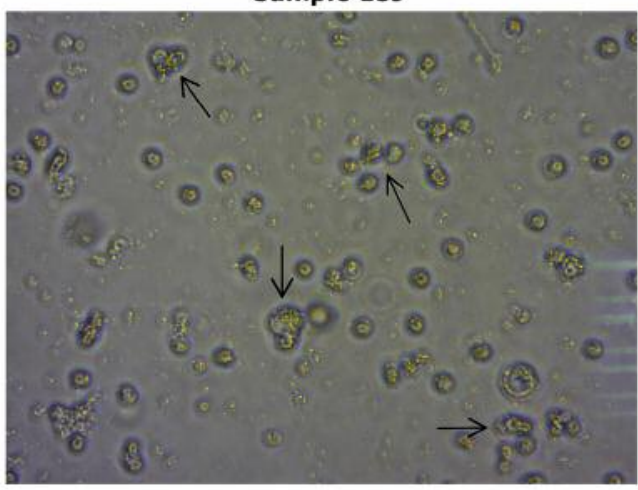

Sample 15L
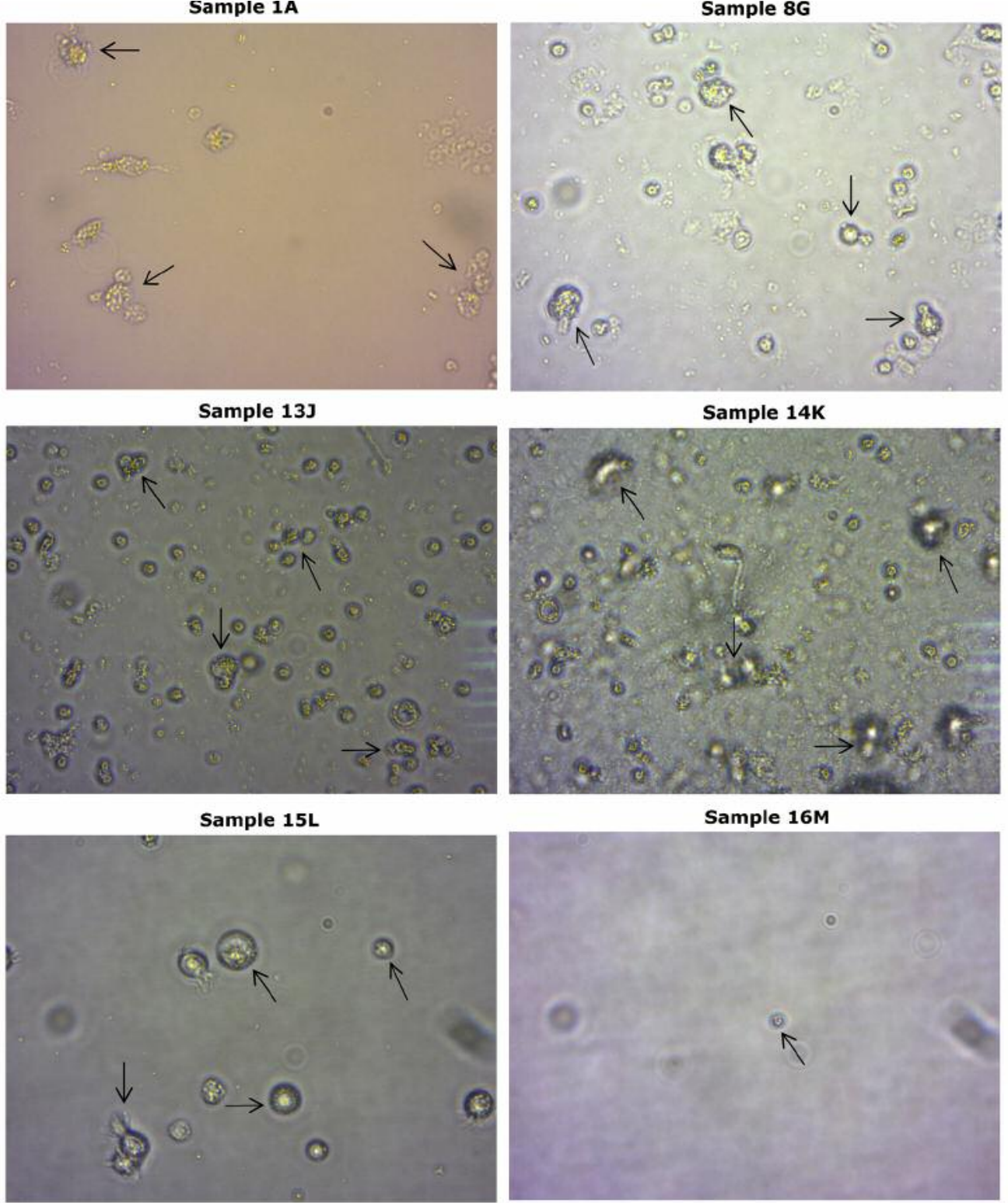

Sample 14K

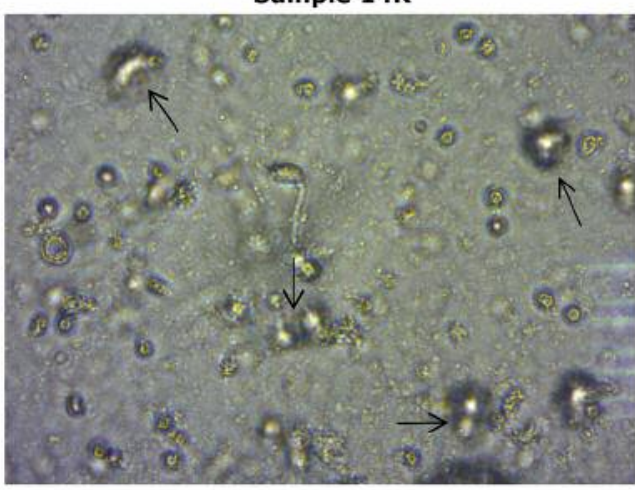

Sample 16M

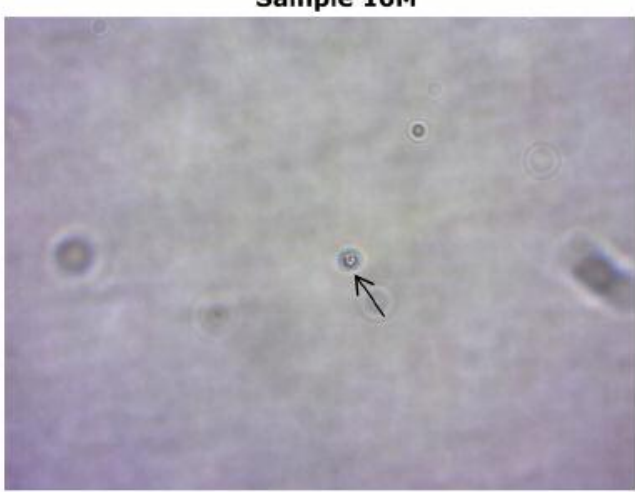

Sample 17N

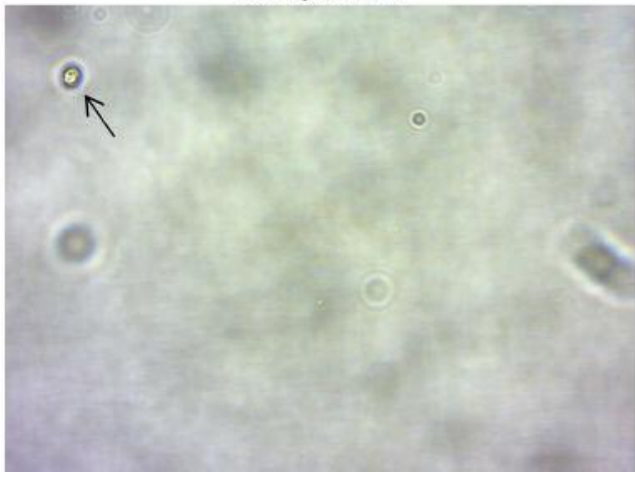

Figure 1. Microscopy images of dendritic cells (DCs), cluster of differentiation (CD) $4^{+}$cells and $C D 19^{+}$cells after 12 days of co-culture. Images are representative of samples $1 \mathrm{~A}, 8 \mathrm{G}, 13 \mathrm{~J}, 14 \mathrm{~K}, 15 \mathrm{~L}, 16 \mathrm{M}$ and $17 \mathrm{~N}$, respectively, after 12 days of co-culture with $\mathrm{DCs}, \mathrm{CD} 4^{+}$cells and CD19+ cells in serum-free medium. Arrows indicate cells with characteristic plasma cell morphology. 


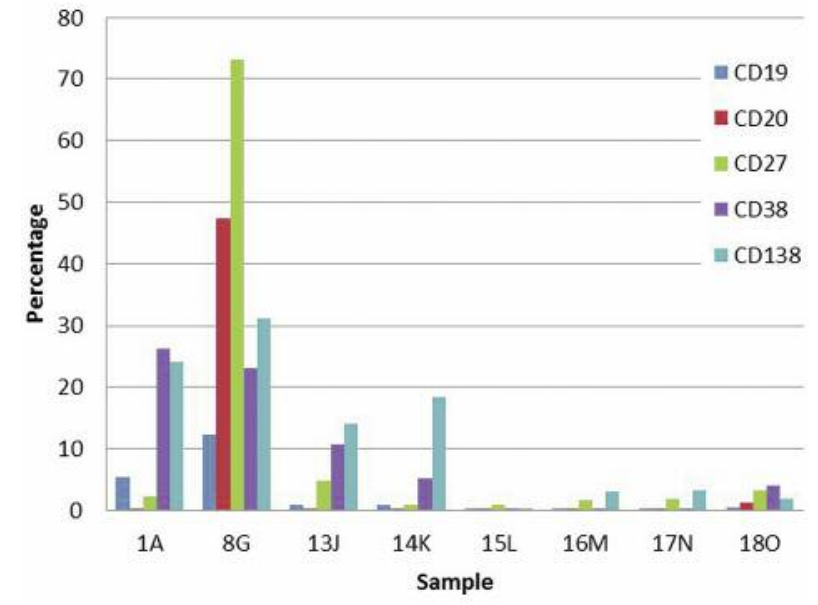

Figure 2. Flow cytometric analysis at day 12 of co-culture. The expression level in negative (unstained) control samples ranged from $0.05 \%$ to $0.5 \%$ which means that they did not express the antigens of interest (data not shown).

consuming, the main disadvantage is that cross-reactivity might occur with the secondary antibody, resulting in nonspecific signals.

Western blot analysis. Next, we used western blotting to detect antibodies specific for the selected epitope. A protein including the sequence of the selected peptide was prepared and probed with an appropriate primary antibody (positive control) and secondary antibody conjugated with alkaline phosphate. The bands were visualized after incubation with NBT substrate. The $\sim 120 \mathrm{kDa}$ band in each sample and positive control corresponded to the expected molecular weight of the antibody. The unique band indicated the presence of a monoclonal antibody against the selected epitope (Figure 5).

\section{Discussion}

The immune system is the natural defence system of the human body. When a foreign antigen enters the body for the first time, the immune system is stimulated and initiates the secretion of specific antibodies against the antigen. The produced antibodies recognize and inactivate the antigen by binding to its surface. This process represents a typical human immune response. Many pharmaceutical companies are interested in producing antibodies in vitro at small, medium and, large scales. Antibodies are used extensively in diagnosis, basic biomedical research, and treating diseases such as cancer.

Currently, many monoclonal antibodies are 'humanized' or fully human. However, both types still have immunological
Sample 1A
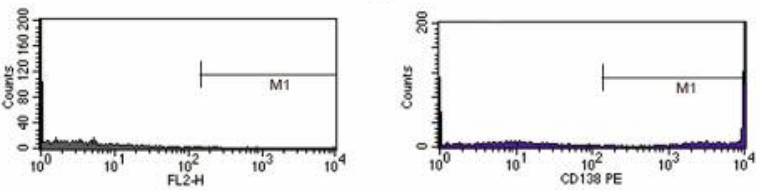

Sample 8G

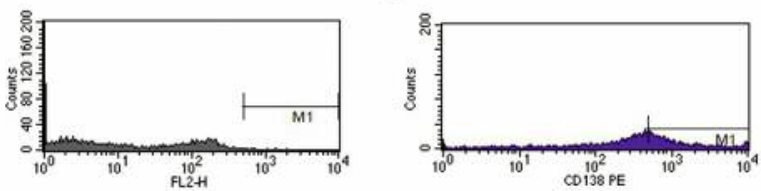

Sample 13]

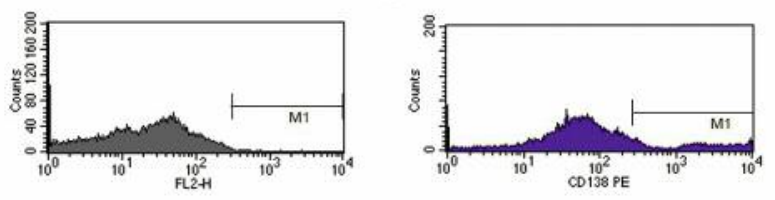

Sample 14K

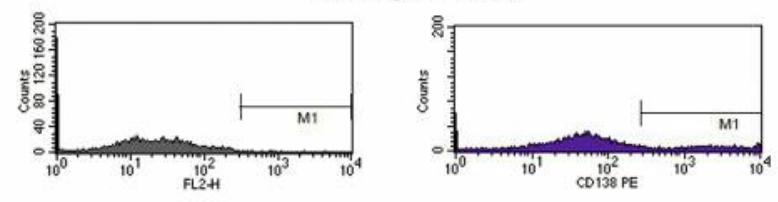

Sample 15L
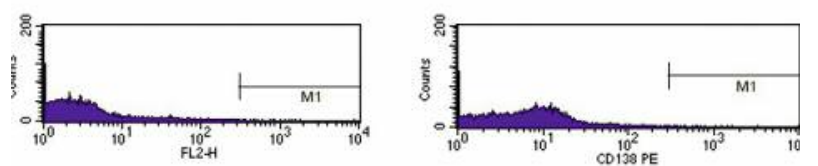

Sample 16M
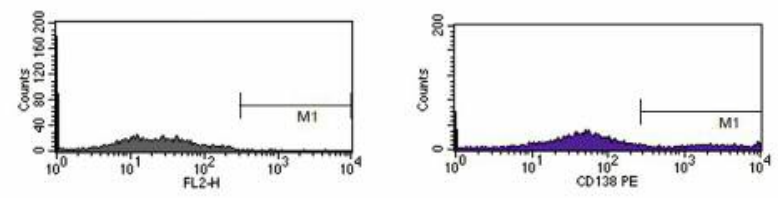

Sample 17N
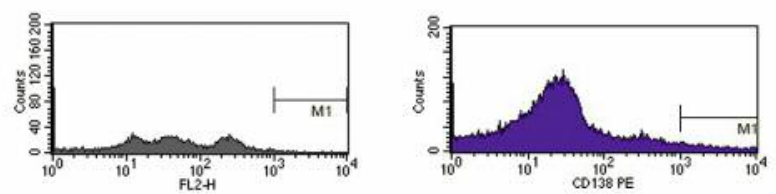

Figure 3. Cluster of differentiation 138 (CD138) expression at day 12 of co-culture.

risks to humans. The first category contains murine sequence-derived complementarity determining regions that have been engrafted along with the necessary framework back mutations into human sequence-derived $\mathrm{V}$ regions. The 


\section{$12^{\text {th }}$ day of harvesting \\ 'panel of 5 ' test : surface antigen expression analysis}

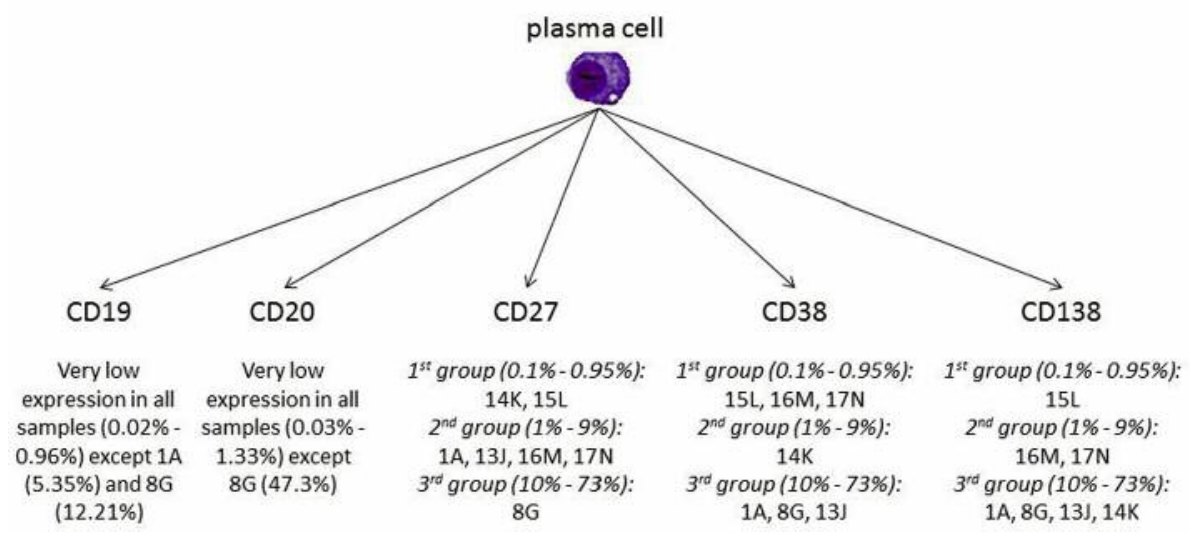

Figure 4. Expression analysis of five surface markers in different samples on the 12th day of harvesting. CD: Cluster of differentiation.

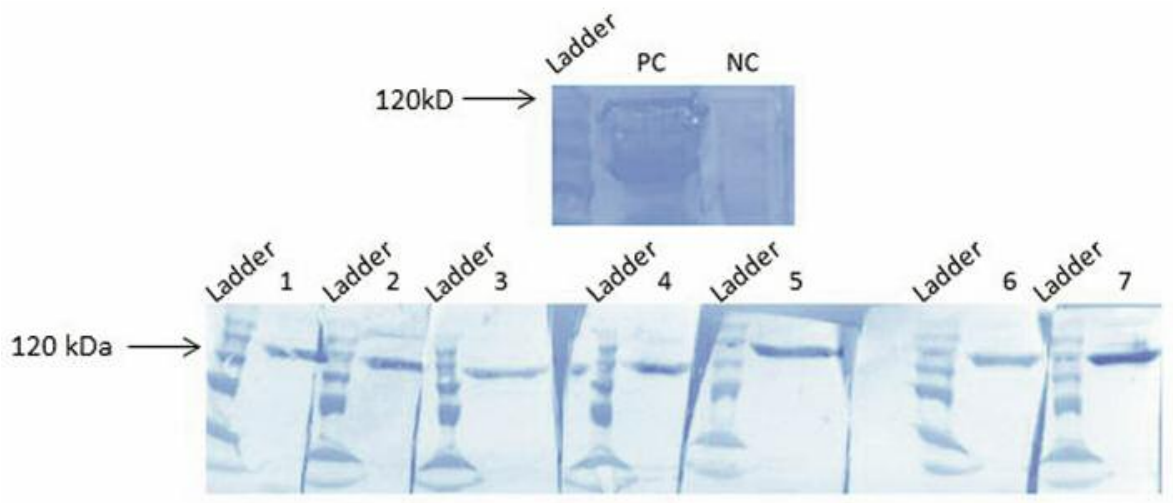

Figure 5. Western blot results of the selected peptide under reducing conditions. Ladder, Precision Plus Protein ${ }^{T M}$ All Blue Prestained Protein Standard ladder (161-0373; BioRad); PC, positive control; NC, negative control, lane 1, sample 1A; lane 2, sample 8G; lane 3, sample 13J; lane 4, sample 14K; lane 5, sample 15L, lane 6, sample 16M, lane 7, sample $17 \mathrm{~N}$.

second category does not contain murine sequences but uses two sources, phage display technology and transgenic mice $(10,11)$.

CD4 ${ }^{+}$T-helper cells are associated with the presence of IgG subclass antibodies during immune responses (11). Although their mode of action is not fully understood, two signals may activate them. The first signal originates from an antigen-presenting cell that introduces a peptide to $\mathrm{CD}^{+}$ T-helper cells. The second signal is provided by $\mathrm{B} 7$ proteins (CD80 and CD86), which is recognized by the CD28 protein on the $\mathrm{CD}^{+}$cell surface (12). A previous study demonstrated that B-lymphocytes can act as antigenpresenting cells for $\mathrm{CD}^{+}{ }^{+}$T-cell priming in vivo (13).
An antigen-specific interaction occurs between T- and Bcells for the secretion of antigen-specific antibodies. CD4 ${ }^{+}$ T-cells bind specifically to the antigen-presenting cell, which introduces a specific antigen, and then an interaction between them and a B-cell occurs. Under certain conditions, the B-cell matures into a plasma cell that produces specific antibodies $(14,15)$. The present study is based on the fact that B-cells are stimulated by T-cells when both cell types recognize the same epitope introduced by an antigenpresenting cell. When this process occurs, plasma cell generation and antibody secretion are observed.

Three distinct cell populations were isolated from healthy donors and cancer patients, and co-cultivated in the presence 
of IL2, IL4, IL10, IL21, anti-CD40L, and anti-IgM. Among the surface molecules involved in T- and B-cell interactions, CD40/CD40L appears to be essential. Although the interaction between CD40 on the surface of B-cells and its ligand (CD40L), which is expressed by activated T-cells, promotes B-cell proliferation, immunoglobulin class switching, and apoptosis abrogation $(16,17)$, CD40L also promotes differentiation into memory B-cells instead of plasma cells (18). More specifically, interruption of the CD40 signal after 3 days in culture leads to terminally differentiated plasma cells, indicating a role of CD40L in the differentiation pathway.

In addition to the cell-to-cell interactions, cytokines play an important role in B-cell differentiation. IL2, IL4, IL10 and IL21 are pleiotropic molecules with a broad spectrum of actions. More importantly, it has been reported that IL2 and IL10 act synergistically with DCs to promote B-cell differentiation in the absence of CD40 signalling in vitro (19, $20)$. It has also been shown that IL10 promotes growth and differentiation of anti-CD40-activated B-cell chronic lymphocytic leukaemia cells (20) Moreover, early IL2 signalling is paramount for the initiation of activated B-cell differentiation into plasma cells, and is not substituted by IL21 signaling. These observations suggest that IL21 has a positive role in plasma cell differentiation at later stages (21).

The role of IL21 in immune responses was investigated by Ozaki et al., who demonstrated that IL21 can induce isotype switching and differentiation of naïve B-cells and enhance Ig and plasma cell production by B-cells that have been activated by the B-cell receptor, but provides apoptotic signals to 'bystander' B-cells responsible for non-specific hypergammaglobulinaemia. Furthermore, the same group showed that combination of IL4, anti-CD40, and anti-IgM signals increases B-cell proliferation in the presence of IL21 $(18,22)$. Another study has shown that PBMCs incubated with anti-CD40, IL4, and IL21 secrete IgG in vitro (23).

At the end of incubation with the above supplements, oval-shaped cells were observed under light microscopy. This kind of cell can be easily distinguished from immature B-cells by their morphological appearance. The nucleus is small, dense and eccentric. Additionally, to characterize this population, a panel of five surface antigens was analyzed by flow cytometry (24). The most widely used membrane antigen is syndecan-1 (CD138). Because of its heterogeneous expression, the tested samples were categorized into three groups. The first group expressed CD138 in only 0.02-0.96\% of cells, in the second expression ranged from $1 \%$ to $9 \%$, and the final group expressed CD138 in $10-73 \%$ of cells. The high expression of syndecan-1 also correlated with high expression of two other markers: CD38, also known as cyclic ADP ribose hydrolase, and CD27, a member of the TNF receptor superfamily (25). In this study, high expression levels of CD27, CD38, and CD138 were found when the sample lacked CD20 and expressed low levels of CD19. CD20 is expressed on the surface of B-cells, starting at the pre-B-cell stage, and on mature B-cells in the bone marrow and periphery. Conversely, there are some controversies concerning CD19. A previous study showed that it is exclusively expressed throughout B-cell development from the pro-B-cell stage up to, but not including, the plasma cell stage (26), whereas another study indicated that plasma cells express this marker at low levels (13). The second scenario is in agreement with the findings of the present study that confirmed low expression $(0.05-0.96 \%)$ of CD19 in five out of the seven samples.

The CD138 surface antigen is the most representative marker to characterize plasma cell populations. In many cases, the donor age is not correlated with its staining density in flow cytometry (27). The present study did not find any correlation between the number of PBMCs, $\mathrm{CD}^{+}{ }^{+}$cells, or $\mathrm{CD} 19^{+}$cells and CD138 expression levels. Additionally, there is no evidence that the ratio between $\mathrm{DCs}$ and $\mathrm{CD}^{+}$cells in co-cultivation may be correlated with higher levels of CD138.

In order to confirm the presence of plasma cells in culture, the production of a specific antibody against the selected peptide was detected in the culture supernatant. An ELISA is a powerful method because it is quick and simple to carry out and can be designed to rapidly handle a large number of samples in parallel. In the present study, we developed an epitope-specific ELISA (28). To confirm the platform, western blot analysis was performed twice. Using this technique, a mixture of proteins is separated based on molecular weight through gel electrophoresis. Data produced by a western blot are typically considered to be semi-quantitative because they provide a relative comparison of protein levels, but not an absolute measure of quantity $(29,30)$.

Other studies produced monoclonal antibodies in vitro using phage display, transgenic mice, or Ig gene cloning and expression in vitro. However, these monoclonal antibodies are not fully human and they may cause toxicity to patients (31). In contrast, the present approach uses a novel platform to produce fully human monoclonal antibodies because the cells are human in origin.

The present study demonstrates the secretion of a fully human antibody against a selected epitope introduced to DCs into the culture supernatant of plasma cells generated under certain cultivation conditions. The procedure strongly recommends the alteration between populations of human DCs, human $\mathrm{CD}^{+}$cells, and human $\mathrm{CD} 19^{+}$cells in the same culture for 12 days. This platform reduces both the cost and time involved in human antibody production. IL2, IL4, IL10, IL21, anti-IgM and anti-CD40L might play a crucial role in the above model. However, even though the results of this study are very encouraging, more analyses should be performed for the production of useful and marketable human monoclonal antibodies. 


\section{References}

1 Liu JK: The history of monoclonal antibody development Progress, remaining challenges and future innovations. Ann Med Surg 3: 113-116, 2014.

2 Zider A and Drakeman DL: The future of monoclonal antibody technology. MAbs 2: 361-364, 2010.

3 Duvall M, Bradley $\mathrm{N}$ and Fiorini RN: A novel platform to produce human monoclonal antibodies: The next generation of therapeutic human monoclonal antibodies discovery. MAbs 3: 203-208, 2011.

4 Liu JK: The history of monoclonal antibody development Progress, remaining challenges and future innovations. Ann Med Surg 3: 113-116, 2014.

5 Peterson NC: Advances in monoclonal antibody technology: genetic engineering of mice, cells and immunoglobulins. ILAR J 46: 314-319, 2005.

6 Ploegh HL: Bridging B-cell and T-cell recognition of antigen. J Immunol 179: 7193, 2007.

7 Caraux A, Klein B, Paiva B, Bret C, Schmitz A, Fuhler GM, Bos NA, Johnsen HE, Orfao A and Perez-Andres M: Circulating human B- and plasma cells. Age-associated changes in counts and detailed characterization of circulating normal CD138- and CD138+ plasma cells. Haematologica 95: 1016-1020, 2010.

8 Ettinger R, Sims GP, Fairhurst AM, Robbins R, da Silva YS, Spolski R, Leonard WJ and Lipsky PE: IL21 induces differentiation of human naive and memory B-cells into antibody-secreting plasma cells. J Immunol 175: 7867-7879, 2005.

9 Dalakas MC: B-Cells as therapeutic targets in autoimmune neurological disorders. Nat Clin Pract Neurol 4: 557-567, 2008.

10 Weiner LM: Fully human therapeutic monoclonal antibodies. J Immunother 29: 1-9, 2006.

11 Harding FA, Stickler MM, Razo J and DuBridge RB: The immunogenicity of humanized and fully human antibodies: residual immunogenicity resides in the CDR regions. MAbs 2 : 256-265, 2010.

12 Ellmeier W: Molecular control of CD4(+) T-cell lineage plasticity and integrity. Int Immunopharmacol 28: 813-817, 2015.

13 Constant SL: B lymphocytes as antigen-presenting cells for CD4+ T-cell priming in vivo. J Immunol 162: 5695-5703, 1999.

14 Lanzavecchia A: Antigen-specific interaction between T- and Bcells. Nature 314: 537-539, 1985.

15 Harwood NE and Batista FD: Visualizing the molecular and cellular events underlying the initiation of B-cell activation. Curr Top Microbiol Immunol 334: 153-177, 2009.

16 Kawabe T, Matsushima M, Hashimoto N, Imaizumi $\mathrm{K}$ and Hasegawa Y: CD40/CD40 ligand interactions in immune responses and pulmonary immunity. Nagoya J Med Sci 73: 6978, 2011.

17 Elgueta R, Benson MJ, de Vries VC, Wasiuk A, Guo Y and Noelle RJ: Molecular mechanism and function of CD40/CD40L engagement in the immune system. Immunol Rev 229: 152-172, 2009.
18 Arpin C, Banchereau J and Liu YJ: Memory B-cells are biased towards terminal differentiation: a strategy that may prevent repertoire freezing. J Exp Med 186: 931-940, 1997.

19 Fayette J, Durand I, Bridon JM, Arpin C, Dubois B, Caux C, Liu YJ, Banchereau J and Briere F: Dendritic cells enhance the differentiation of naive B-cells into plasma cells in vitro. Scand J Immunol 48: 563-570, 1998.

20 Fluckiger AC, Garrone P, Durand I, Galizzi JP and Banchereau J: Interleukin 10 (IL10) up-regulates functional high affinity IL2 receptors on normal and leukemic B lymphocytes. J Exp Med 178: 1473-1481, 1993.

21 Le Gallou S, Caron G, Delaloy C, Rossille D, Tarte K and Fest T: IL2 requirement for human plasma cell generation: coupling differentiation and proliferation by enhancing MAPK-ERK signaling. J Immunol 189: 161-173, 2012.

22 Ozaki K, Spolski R, Ettinger R, Kim HP, Wang G, Qi CF, Hwu P, Shaffer DJ, Akilesh S, Roopenian DC, Morse HC, 3rd, Lipsky $\mathrm{PE}$ and Leonard WJ: Regulation of B-cell differentiation and plasma cell generation by IL21, a novel inducer of BLIMP1 and BCL6. J Immunol 173: 5361-5371, 2004.

23 Wijkhuisen A, Savatier A, Cordeiro $\mathrm{N}$ and Leonetti $\mathrm{M}$ : Production of antigen-specific human IgGs by in vitro immunization. BMC Biotechnol 16: 22, 2016.

24 Calame KL: Plasma cells: finding new light at the end of B-cell development. Nat Immunol 2: 1103-1108, 2001

25 Kumar S, Kimlinger T and Morice W: Immunophenotyping in multiple myeloma and related plasma cell disorders. Best Pract Res Clin Haematol 23: 433-451, 2010.

26 Vale AM and Schroeder HW Jr.: Clinical consequences of defects in B-cell development. J Allergy Clin Immunol 125: 778$787,2010$.

27 Tiemann K, Weigel MT, Alkatout I, Wenners AS, Mundhenke H, Schafer FW, Bauer M, Schem C, Maass N, Jonat W and Mundhenke C: Significance of syndecan-1 expression in ductal carcinoma in situ of the breast. Anticancer Res 34: 3607-3616, 2014.

28 Chevrier MC, Chateauneuf I, Guerin M and Lemieux R: Sensitive detection of human IgG in ELISA using a monoclonal anti-IgG-peroxidase conjugate. Hybrid Hybridomics 23: 362367, 2004.

29 Liu ZQ, Mahmood T and Yang PC: Western blot: technique, theory and trouble shooting. N Am J Med Sci 6: 160, 2014.

30 Mahmood T and Yang PC: Western blot: technique, theory and trouble shooting. N Am J Med Sci 4: 429-434, 2012.

31 Schroff RW, Foon KA, Beatty SM, Oldham RK and Morgan AC, Jr.: Human anti-murine immunoglobulin responses in patients receiving monoclonal antibody therapy. Cancer Res 45: 879-885, 1985.
Received July 6, 2016

Revised July 27, 2016

Accepted August 2, 2016 